\title{
TWO WAYS TO UNDERSTAND THE COMMON LAW
}

\begin{abstract}
$\underline{\text { Abstract }}$
I distinguish between two ways of understanding the effect of a decision as a precedent in the common law, which I refer to as the individual rule approach and the holistic approach. I consider the different versions of the common law that they would be expected to give rise to, which approach is more closely reflected in the practices of the common law, and why the holistic approach is preferable as a method for finding and developing the law in adjudication. I explain why under the holistic approach the common law contains principles as well as rules, and I consider the two approaches in the light of the requirement of the rule of law, and I show how the holistic approach explains a version of the policy/principle distinction.
\end{abstract}

Key words: Precedent, common law, analogical reasoning, rule of law, policy, principle, Dworkin.

\section{INTRODUCTION: TWO WAYS TO UNDERSTAND A PRECEDENT}

The common law has been created by the decisions of the courts as precedents. To understand it, we need to know what contribution a decision makes to the law, how it makes law or alters the law. This contribution is usually understood as the ratio decidendi or holding of a decision. Curiously, there is no consensus on how to establish what the ratio or holding of a decision is. ${ }^{1}$ On one view, the ratio of a case is simply the rule adopted by the court to decide it. The rule defines a category of factual situations for which a certain legal consequence applies. This category obviously includes the facts of the case in question, and encompasses other situations that the rule treats as equivalent, where it also applies. Thus the rule might provide that, where the facts are $\mathrm{X}, \mathrm{Y}$ and $\mathrm{Z}, \mathrm{C}$ has a claim against $D$, the facts of the case being particular examples of facts meeting the descriptions $X, Y$ and Z. On this approach, a court will apply a rule laid down previously if there is such a rule that applies to the facts of the case, and, if there is no applicable rule, it will formulate a new rule to apply, according to its judgement of the relevant moral considerations, thereby making new law. Thus the

\footnotetext{
${ }^{1}$ See, for example, William Twining \& David Miers, How to Do Things with Rules $5^{\text {th }}$ edn (Cambridge: CUP, 2010) at 304-12; Frederick Schauer, "Precedent" in Andrei Marmor, ed, The Routledge Companion to the Philosophy of Law (Routledge 2015). "Doctrine of precedent" and "stare decisis" are commonly used not in connection with the question of the ratio decidendi or holding of a decision in this sense, but in connection with the hierarchy of courts with respect to their authority for later courts, which I do not discuss.
} 
Author: Peter Jaffey, University of Leicester

law is built up rule by rule, each decision either applying an existing rule or making a distinct contribution in the form of a new rule.

However, it is open to question whether this simple account, which I will call the individual rule approach, is consistent with the way in which the courts draw on previous decisions in practice. It has seemed to many commentators that the ratio of a previous decision is not necessarily the rule that the earlier court chose to apply. It might then seem, as some sceptics have concluded, that in reality a court can simply impute to a previous case whatever ratio it wishes in order to decide the case before it as it thinks fit, and therefore that the whole idea of the common law as a body of precedents binding later courts is an illusion.

According to the alternative approach that seems to me preferable, there is another way of understanding how a decision acts as a constraint on future decisions. On this approach, a court formulates a rule to apply, which it takes to represent the law, but what is binding in the decision for a future court is not this rule, but the decision itself, the outcome on its facts, in the following sense. A later court invoking the decision must treat it as correctly decided, and of course must accept its findings of fact, but it is free to make its own determination of the rule that applies to determine the result where the facts are as they were in that case. Thus it may consider different facts to be crucial or characterise them differently. On this approach, invoking a previous decision as a precedent involves constructing a rule consistent with the decision that also applies to the facts in the current case. $^{2}$

One might object that the requirement to construct a rule consistent with the previous decision is not a constraint at all, and that a later court is free of any constraint unless it is bound to

\footnotetext{
2 Alexander discusses the "result model" of precedent in Larry Alexander, "Constrained by Precedent" 63 S Cal L Rev 1 (1989), but the approach he discusses is different from the approach suggested here. Alexander also discusses the "rule model", which corresponds to the individual rule approach. See also Grant Lamond, "Do Precedents Create Rules?" 11 Legal Theory 1 (2005). See also Peter Jaffey, "Authority in the Common Law" (2011) 36 Australian Journal of Legal Philosophy 1. The holistic approach is not the same as a weak rule or presumptive rule model of precedent: see below $\mathrm{n} 8$. In the literature on the nature of the ratio decidendi, it is often assumed that the ratio is a rule determined by the decision and the controversy is over how to establish from the judgement what this rule is, that is to say what part of the judgement constitutes the ratio: see e.g. Arthur L Goodhart, "Determining the Ratio Decidendi of a Case" 40 Yale Law Journal 161 (1930). This longstanding controversy over how to determine the ratio suggests, consistently with the alternative approach, that the ratio cannot be understood in this way at all: see below, at $n 6$.
} 
Author: Peter Jaffey, University of Leicester

apply the rule laid down in the decision. The later court can always devise a rule that distinguishes between the facts of the new case and the facts of the old case, to the effect that the old case does not apply as a precedent on the facts of the new case, and conversely it can always devise a rule, if necessary in a very general form, that is applicable on both the facts of the old case and those of the new one, to the effect that the old case acts as a precedent applicable on the facts of the new case. ${ }^{3}$

However, in my view earlier cases do genuinely constrain later courts on this approach. The court is not constrained in the sense that a certain result is dictated by the requirement to apply a binding rule previously laid down, but the court cannot make a determination free of any constraint. The constraint operates through an exercise of moral judgement. A later court has to decide in the same way as a previous decision if it cannot construct a rule that differentiates between the present case and the previous one, that is to say, if it considers that there is no material difference between them. A single decision on its own may be a weak constraint, because there may be a wide range of morally-plausible rules consistent with it, but with many previous decisions, all taken to be correct, the number of morally-plausible rules consistent with them is much reduced. On this alternative approach, previous decisions do not operate as precedents independently of each other. A later court has to construct a rule or body of rules that is consistent with previous decisions taken together, and previous decisions generate the constraint collectively. Thus I will refer to this approach as the holistic approach. ${ }^{4}$

On both approaches - the individual rule approach and the holistic approach - the outcome of a case may not be dictated by previous decisions, and the court may be required to exercise its own moral judgement, pursuant to its duty to do justice. However, the way in which moral judgement is exercised, and the way it affects the law, are different on the two approaches. Under

\footnotetext{
${ }^{3}$ See, for example, Alexander, ibid, 38; Frederick Schauer, Playing by the Rules (Oxford: Clarendon Press, 1991) at 184. ${ }^{4}$ Many writers have described the common law as holistic or collective or coherence-based in different ways, including Ronald Dworkin, Taking Rights Seriously (London: Duckworth, 1977), especially ch 4, and Law's Empire (London: Fontana, 1986); Michael S Moore, "Precedent, Induction, and Ethical Generalisation" in Laurence Goldstein, ed, Precedent in Law (Oxford: Clarendon Press, 1987); SL Hurley, “Coherence, Hypothetical Cases, and Precedent" (1990) 10 OJLS 221; Ernest J Weinrib, Corrective Justice, (Oxford: OUP, 2012), ch 2; Alan Brudner with Jennifer M Nadler, The Unity of the Common Law, $2^{\text {nd }}$ edn (Oxford OUP, 2013). Historically it was often described in this way: see for example Gerald J Postema, Bentham and the Common Law Tradition (Oxford: Clarendon Press, 1986) at 66-69.
} 
Author: Peter Jaffey, University of Leicester

the individual rule approach, the court exercises moral judgement to make a new rule where no applicable rule has been laid down in a previous decision, whereas under the holistic approach the exercise of moral judgement is part of the process of constructing an applicable rule that is consistent with previous decisions.

In this article, I will consider how the common law and common law reasoning would be expected to operate according to these two different approaches, which approach gives an account of the law and legal reasoning closer to what we find in the common law, and which would be a preferable approach for the common law to adopt. As will become apparent, the contrast between these approaches largely mirrors the debate between Ronald Dworkin and his critics, though the starting point is different and the discussion is focussed on the common law.

\section{SOME FEATURES OF COMMON LAW REASONING}

Certain basic features of the common law differ according to whether they are understood in accordance with the individual rule approach or the holistic approach.

\section{The ratio}

On the individual rule approach, the ratio is the rule laid down by the original court in its decision and it is fixed from then. ${ }^{5}$ This is difficult to reconcile with the controversy that often surrounds the ratio of a case. ${ }^{6}$ If a decision has a fixed ratio that was laid down in the judgement, why is it so often controversial what the ratio of a decision is? On the holistic approach, the ratio of a decision meaning the ratio imputed to the decision - is the rule that would now be applied to the facts of that case according to an holistic account of all the cases, and the decision is taken to support this rule because the rule accounts for the outcome in the case. On this approach, the ratio may not be the rule intended by the original court. It may be at a higher or lower level of generality, for

\footnotetext{
${ }^{5}$ See for example Joseph Raz, The Authority of Law (Oxford: Clarendon Press, 1979) at 183-4. Under the individual rule approach, the court makes law by exercising a normative power to do so, whereas under the holistic approach the court exercises a normative power to decide the case, but not to make law, since the contribution to the law is not necessarily the rule it applies to decide the case.

${ }^{6}$ It leads to the "buried treasure" or "secret book" conception of the ratio, according to which there is a true and fixed but obscure or disguised ratio: see Twining \& Miers, above n1, at 306, and Dworkin, Taking Rights Seriously, above n4, at 337.
} 
Author: Peter Jaffey, University of Leicester

example. It may recognise different facts as material to the decision, or characterise the material

facts differently. It is liable to change, and it depends on other decisions and on moral

considerations, though as a settled body of law develops a settled understanding of the ratio is likely

to form. This approach seems to me closer to practice, and it is also consistent with the heavily fact-

focussed common law style of judgement, which gives a full account of the surrounding facts, going

beyond what the court itself considers is strictly relevant in the light of the rule it applies to decide

the case. ${ }^{7}$

\section{Conclusive or provisional rules?}

Under the individual rule approach, a rule laid down in a decision constitutes the relevant law where

it is applicable. On the holistic approach, although a court is required to formulate a new rule (in

accordance with previous decisions) as the basis for its decision, it is not necessarily the applicable

law for the future. A later court may adopt the rule and apply it as the law, or it may modify the rule, or it may adopt a different rule, provided that it accounts for previous decisions. Thus any rule laid down is merely provisional. ${ }^{8}$ (This is not to say that the decision itself is not final.)

This understanding of rules as provisional is consistent with the standard practice of

distinguishing. As the practice is normally understood, when a court is faced with a rule laid down in an earlier case that applies to the facts of the new case, and it takes the view that the new case is materially different from the earlier one and should be decided differently, it can modify the rule laid down in the earlier case to exclude the new case from its scope, thereby distinguishing the

\footnotetext{
7 On both the individual rule approach and the holistic approach, much of a judgment consists of reasoning that is not itself authoritative. Various writers have discussed features of common law reasoning that reflect the holistic approach more closely than the individual rule approach: see for example Julius Stone, "The Ratio of the Ratio Decidendi" (1959) 22 MLR 597; AWB Simpson, "The Common Law and Legal Theory" in Oxford Essays in Jurisprudence, Second Series (Oxford: OUP, 1973); Heidi Hurd, "Sovereignty in Silence" 99 Yale Law Journal 945 at 947 (1990); Stephen R Perry, "Judicial Obligation, Precedent, and the Common Law" (1987) 7 OJLS 215 at 234-9; see Larry Alexander \& Emily Sherwin, Demystifying Legal Reasoning (Cambridge: CUP, 2008) at 49; Margaret Martin, Judging Positivism (Oxford: Hart Publishing, 2014) at 35-6. 8 I take a rule to be conclusive with respect to matters within its scope, which seems to me the usual understanding. A provisional rule purports to be an ordinary rule in this sense but need not be taken as such, i.e., it is not authoritative as such. Various commentators have understood the common law in terms of a weak form of rule: see for example Frederick Schauer, "Is the Common Law Law?" 77 Cal L Rev 455 (1989); Melvin Aron Eisenberg, The Nature of the Common Law (Cambridge, Mass: Harvard University Press, 1988) at 65; Theodore M Benditt, "The Rule of Precedent" in Goldstein, above n4, at 95; Stephen R Perry, "Judicial Obligation, Precedent, and the Common Law" (1987) 7 OJLS 215 at 225. On the suggested approach a precedent is authority for the result in the decision not the provisional rule.
} 
Author: Peter Jaffey, University of Leicester

earlier case. It determines that the law is in the form of the modified rule, which continues to account for the previous decision. ${ }^{9}$ Distinguishing understood in this way is consistent with the provisional character of rules under the holistic approach, but it appears to be at odds with the individual rule approach. According to the individual rule approach, the rule in the form laid down by the earlier court must be correct and constitutes the law until, in distinguishing the case, the court now changes the law by modifying the rule. This means that the court can substitute and immediately apply a new rule as the law, whenever it takes the view that this would be a just outcome. This seems quite inconsistent with the proposition that the rule laid down by the previous court constituted the law. Some commentators say that in distinguishing an earlier case a court does not modify a rule previously laid down, but instead simply determines that the rule originally laid down in that case is narrower than it has hitherto been understood to be, ${ }^{10}$ but this seems a very implausible account of the actual practice of distinguishing, and it denies or obscures the important difference between modifying a rule laid down in an earlier decision so that it does not apply to the facts of the new case, and construing the rule as laid down in the earlier decision to establish that it does not apply on these facts.

\section{Incomplete or complete and gapless?}

On the individual rule approach, an issue arising for a court will either fall under a binding rule, or in a gap between rules where no rule has previously been laid down. ${ }^{11}$ Where no rule has previously been laid down, the court has to devise a new rule, which it does free of the constraints of previous decisions. ${ }^{12}$ Thus the law has a binary or dichotomous character. On the holistic approach, the law does not have this binary character. There are neither situations that fall under a binding rule, nor

\footnotetext{
${ }^{9}$ See for example HLA Hart, The Concept of Law $3^{\text {rd }}$ edn (Oxford: Clarendon Press, 2012) at 134-5; Raz, above n5, at 183-9; Melvin A. Eisenberg, "The Principles of Reasoning in the Common Law" in DE Edlin, ed, Common Law Theory (Cambridge: CUP, 2007).

${ }^{10}$ This is the possibility described by Raz as the "tame view": Raz, above n5, at 185-6. See Nigel E Simmonds, Central Issues in Jurisprudence (Sweet \& Maxwell, $4^{\text {th }}$ edn, 2013).

11 The law is "fundamentally incomplete": see Hart, postscript to The Concept of Law, above n9, at 272-76; Raz, above n5, at 181-2; Andrei Marmor, Philosophy of Law (Princeton: Princeton University Press, 2011) at 84-5. The gap includes the "open texture" of general terms of a rule: see Hart, above n9, 119-120.

12 As a matter of discretion, as it is generally put, following Hart, above n9, at 132.
} 
Author: Peter Jaffey, University of Leicester

gaps where no previous decision is applicable. The court always has to devise a rule that applies to the facts in issue, and is also consistent with previous decisions. In this way it is always constrained by previous decisions, though it also has to exercise moral judgement to make its determination as between the different possible rules that are consistent with previous decisions. Some would say that ordinary legal argument in the common law does show that it has a binary character, with gaps in the law, whereas others would say, as it seems to me, that legal argument treats it as complete and gapless or continuous, as the holistic approach implies it to be.

The difference between the individual rule approach and the holistic approach on this issue is reflected in a protracted argument between Dworkin and his critics. On the individual rule approach, there can be circumstances in which the existing law does not provide that $\mathrm{C}$ has a right to compensation on certain facts, nor that $\mathrm{C}$ does not have a right to compensation. There is a gap in the law and no rule previously laid down applies on the facts. One cannot infer from the fact that $C$ does not have a right to compensation that $D$ has a right not to pay compensation. To settle the dispute, the court will have to make new law by devising a new rule. On the holistic approach, there are no gaps in the law and if the law does not give $\mathrm{C}$ a right to compensation on certain facts, it must be the case that it gives $D$ the right not to pay compensation on those facts.

In connection with his hypothetical "Sorensen" case, ${ }^{13}$ which concerned a claim for compensation in negligence in the absence of settled law, Dworkin insisted that, since it was clear that moral judgement has to be exercised in such a case to reach a decision in adjudication, it must be wrong to hold, as his positivist critics do, that determining what the law is does not involve an exercise of moral judgement. ${ }^{14}$ Dworkin assumed that the exercise of moral judgement involved in the adjudication was part of the process of determining the existing law. In my view, this is also normally assumed in legal practice, and under the holistic approach it is true, and this does appear

\footnotetext{
${ }^{13}$ See Ronald Dworkin, Justice in Robes (Cambridge, Mass: The Belknap Press of HUP, 2006) at 143-45.

${ }^{14}$ Hart, above n9, at 200-12; Raz, above n5, ch 3.
} 
Author: Peter Jaffey, University of Leicester

to present a problem for positivism. ${ }^{15}$ But if the individual rule approach is assumed, Dworkin's argument would fail, because although in such a case the judge exercises moral judgement in adjudication, he does so only to make new law, and not to determine what the existing law is. Dworkin's critics, assuming the individual rule approach, objected that Dworkin was running together two separate questions, namely what the existing law is, and what the outcome of the case should be ${ }^{16}$ but on the holistic approach it is not possible to separate out these two questions. Dworkin thought that what was at stake here was an issue of political philosophy, ${ }^{17}$ but ostensibly at least what divides the two approaches is the more prosaic issue of how to understand the effect of previous decisions as precedents in the common law.

The declaratory theory of the common law - the theory that the court always applies subsisting law - is the traditional understanding of the common law, though it is now said to be archaic. Under the individual rule approach, the declaratory theory implies that the court always declares and applies a binding rule previously laid down, which implies that the law is fixed and complete, but this cannot be the case - there must be gaps where the court does not apply existing law. ${ }^{18}$ It seems that, under the individual rule approach, in always purporting to declare and apply existing law, the courts commit themselves to a fiction, presumably in order to avoid appearing to apply new law retrospectively. ${ }^{19}$ However, the holistic approach conforms to the declaratory theory: under the holistic approach the law is complete and gapless and even a newly-formulated rule

\footnotetext{
${ }^{15}$ I will not consider how positivism should be understood more generally, or more particularly whether the holistic approach is consistent with "inclusive positivism".

${ }^{16}$ See in particular Brian Leiter, "The Theory of Esoteric Law", University of Texas Law, Public Law Research Paper no 121, 3-4. Similarly it is common to say that Dworkin fails to distinguish between a theory of law and a theory of adjudication. 17 Dworkin, above n13, 143-6. Dworkin's "one system" approach to law is discussed in Lawrence G Sager, "Putting Law in its Place" in W Waluchow \& S Sciaraffa (eds), The Legacy of Ronald Dworkin (OUP, 2016). Dworkin also thought that the positivist approach involved the "semantic sting" fallacy, but the individual rule approach at least does not seem to involve a conceptual error along those lines.

${ }^{18}$ The view that it is complete is formalism, which is obviously untenable. On my understanding, formalism in this sense does not refer to a "gapless" system such as under the holistic approach where the law depends on moral considerations, nor to formalism in corrective justice theory.

19 This is why it is dismissed as a myth or a fairy tale. Lord Reid, "The Judge as Law Maker" (1972-3) JSPTL (NS) 22; J M Finnis, "The Fairy Tale's Moral" (1999) 115 LQR 170; Hart, above n9, in the postscript, at 274; Marmor, above n11, at 90. See also Allan Beever, "The Declaratory Theory of Law" (2013) 33 OJLS 421: according to Beever, the court declares new law by drawing on legal principles, which is consistent with the position taken here, but Beever treats legal principles as being distinct from positive law and it is not clear how there can be legal principles that are not part of the positive law. Cf Alexander's characterisation of Dworkin's approach in "Was Dworkin an Originalist?" at 300 in Waluchow \& Sciaraffa above n17.
} 
Author: Peter Jaffey, University of Leicester

represents existing law and does not have retrospective effect, since the law cannot be dissociated from the rule constructed by the court to account for previous decisions. Of course, here nonretrospectivity does not mean that the law can always be established in advance in the form of binding rules previously laid down, and so one might think that it is in some sense an illusion. (I shall come back to this later.)

\section{LEGAL RULES AND PRINCIPLES}

According to Dworkin, there is, famously, a distinction in the common law between rules and principles, in the following sense ${ }^{20} \mathrm{~A}$ rule is conclusive or dispositive, in the sense that it can be applied to a set of facts to reach a definitive conclusion as to the legal position on those facts. Thus a rule can be expressed by defining the types of factual situation that fall under the rule, for which the rule provides a certain legal consequence. This does not mean that a rule has to be formulated with complete precision, or that its application does not involve evaluation. A rule may have been stated in an incomplete form, in the sense that it does not provide fully for all the circumstances that fall within its scope and so may need to be refined or supplemented in order to be applied in particular circumstances. However, although a rule may to some degree leave matters open for moral judgement, it purports overall to encompass all the relevant considerations, in the sense that once it has been established what the rule requires (moral judgement having been exercised so far as required for the application of the rule in the circumstances), the rule can be applied to the facts to determine the legal position definitively, without reference to any other considerations.

By contrast, a principle is not dispositive but has weight. If a certain set of facts falls under it, the principle provides a reason for a certain decision - it counts in favour of the decision - without requiring it. This is not because of a lack of precision. The applicability of the principle on the facts may be perfectly clear. The point is that, as a principle, it does not purport to be final, that is to say, it does not purport to take account of all relevant considerations. It has to be weighed against other

20 Dworkin, Taking Rights Seriously, above n4, at 22-28 and 71-80. 
Author: Peter Jaffey, University of Leicester

considerations that may outweigh it and lead to a contrary result. This is generally because the principle is abstract in the sense that it determines the position for an artificial, generic situation rather than a particular set of facts. For example, the principle that agreements should be performed supports the recognition of rights arising from an agreement, whenever there is an agreement, but it may be outweighed in particular circumstances by other, competing principles or other considerations, for example that the principle should not operate in domestic relations, or that in particular circumstances it would be against the public interest for an agreement to be legally binding. The rules of contract law give concrete effect to the principle by specifying exactly the circumstances in which an agreement is legally binding, taking account of the principle and all other considerations. The rules are definitive when they are applicable, but the underlying principle may be relevant but outweighed, and so not given effect, though it remains a sound principle.

It is sometimes said, instead, that a principle is a rule that is not well specified or is vague or has gaps. Rules vary widely in terms of how fully specified they are, and so on this view a principle is a rule lying towards one end of a range, differing from more fully specified rules as a matter of degree. ${ }^{21}$ In this sense a principle, like a rule, purports to be conclusive, even when it is for the moment incompletely specified. No doubt usage is inconsistent, but the usage suggested above reflects a useful distinction because principles in the suggested sense have a distinct role in legal reasoning.

The ratio of a decision is the rule for which a decision stands, or is taken to stand. Under the individual rule approach, this is the rule stated by the court at the time, whereas under the holistic approach it is the rule that forms part of a holistic account of previous decisions, which may differ from the rule laid down in the case. In either case, a ratio is necessarily a rule, and not a principle (in the suggested sense), because it determines the position conclusively on the facts of the case. To say that a rule is the ratio of a case is to say that this rule, applied to the facts of the case, is conclusive

\footnotetext{
${ }^{21}$ See e.g., Joseph Raz, "Legal Principles and the Limits of Law" 81 Yale Law Journal 842 (1972); Marmor, above n11, at 86; Hart, above n9, postscript at 259-63.
} 
Author: Peter Jaffey, University of Leicester

of the outcome on the facts. It would not otherwise count as an adequate justification for the decision. This means that, on the individual rule approach, the law consists only of rules, the rules formulated and laid down by courts in making decisions. The law consists simply of the aggregation of the distinct rules laid down in previous decisions. The individual rule approach has no room for principles in the law. A court either applies legal rules, or, if there is a gap in the law, it devises a new rule which constitutes new law. In exercising its moral judgement to make new rules, a court may draw on moral principles, but these are not part of the law.

On the holistic approach, the law cannot be equated with rules laid down as the ratios of previous cases. These are merely provisional rules and do not constitute the law. What then are the constituent elements of the law, if not rules laid down previously? On the holistic approach, the courts treat not the rules laid down in previous decisions but the decisions on their facts as legally correct. This makes sense only on the assumption that these decisions are morally sound on their facts, and that the law is constructed as an account of justice that accords with them. On this understanding, any concept that has a place in an account of justice can be an element of the law, including principles. A principle is an element of the law if it provides a sound moral basis for the rules that account for previous decisions. For example, there are many decisions that give support to the principle that agreements should be kept. In determining what the law is, a court may invoke the principle, as the principle that lies behind previous cases, and devise new rules to give effect to it in new situations. Furthermore, the law can contain very general principles that are wide enough to be relevant to various areas of the law, which courts may draw on in the process of "theoretical ascent", that is to say increasing generality and abstraction in moral theorising over the construction of rules. ${ }^{22} \mathrm{~A}$ legal principle, although it is part of the law on the holistic account, is not the ratio of any particular case, since (as pointed out above) only a rule can be the ratio of a case. Although I think most lawyers do think of some principles at least as being part of the common law, by virtue of

\footnotetext{
${ }^{22}$ See Dworkin, above $\mathrm{n} 13$, at 25 and 53. This amounts to a version of Dworkin's "law as morality" approach. The holistic approach thus allows for "theoretical disagreement" over what the law is on some issue, as Dworkin argued was is the case in the common law, as opposed to disagreement over what rules have been laid down.
} 
Author: Peter Jaffey, University of Leicester

the support they derive from previous decisions, it is also generally thought, inconsistently, that the common law is composed exclusively of the ratios of cases.

Similarly, with respect to rights, under the individual rule approach legal rights arise only from rules laid down, and, in a gap, in the absence of a rule, there are no legal rights. But under the holistic approach, if we take justice to be fundamentally a matter of interpersonal justice or moral rights (including their correlates in the form of duties and liabilities), the rules formulated by the courts aim to identify and specify these as already subsisting legal rights. One can distinguish between concrete (though provisional) legal rights, which are rights defined by a rule, and abstract rights, which subsist in the law, awaiting specification by a rule, as it were, and correspond to legal principles or other considerations that support previous decisions. In formulating a new rule in the light of legal principles, one might say that the court weighs up abstract legal rights corresponding to legal principles to determine the concrete legal rights that are defined by the rule. For example, in the case of the principle of agreement, there might be an abstract right to the performance of an agreement, though in a particular case there is no concrete right because the principle is outweighed by other considerations that weigh against enforcement. This is, of course, the Dworkinian picture of the common law, but on the account given its basis lies in a certain understanding of precedent. ${ }^{23}$ Various commentators have criticised Dworkin's approach to legal principles, according to which there are principles in the law and identifying them involves the exercise of moral judgement. ${ }^{24}$ One objection is that, although there are indeed principles in the law as well as rules, this is so because they have been introduced into the law by previous decisions in the same way as rules, and that Dworkin was wrong to say that an exercise of moral judgement is involved in identifying legal principles. ${ }^{25}$ But this cannot be the case on either the individual rule approach or

\footnotetext{
${ }^{23}$ Dworkin, above $\mathrm{n} 20$.

${ }^{24}$ As part of his critique of HLA Hart's theory of positivism, Dworkin insisted that Hart's theory recognised only legal rules and that to the contrary there are principles in the law as well as rules: Dworkin, above n20, at 22ff. Dworkin's argument for legal principles was that judges often invoked principles in their reasoning. Hart denied that his theory implied that the law does not contain principles: Hart, above n9, postscript at 259-63.

${ }^{25}$ See e.g. Hart, above n9, postscript at 263-67; D Lyons, "Principles, Positivism, and Legal Theory" 87 Yale Law Journal 415 (1977). This may be true with respect to statutes, as Hart points out, but it is not true of the common law on the individual rule approach.
} 
Author: Peter Jaffey, University of Leicester

the holistic approach. On the individual rule approach, there can only be rules and not principles in the law, because only a rule can be the ratio of a case. On the holistic approach, there are legal principles but a legal principle is not introduced into the law by the decision of court to make it the ratio of its decision. A legal principle is part of the law because it provides a sound moral basis for a body of decisions. ${ }^{26}$

Another criticism has been that Dworkin confused legal principles with moral principles, and that there are no legal principles, though there are moral principles that judges are bound to take account of. On the individual rule approach, judges do not have to take account of principles in determining the existing law, but they have a legal duty as judges to take account of moral principles when they make new law by devising new rules to fill gaps in the existing law. This does not mean that these moral principles are part of the law. By analogy, sometimes a judge has a duty to take account of foreign law, but this does not mean that the foreign law is part of English law. ${ }^{27}$ From this perspective, Dworkin made the mistake of thinking that a moral principle is part of the law because a judge is required to take account of it by virtue of his duty to make new law in the exercise of his moral judgement. ${ }^{28}$ But under the holistic approach it is indeed necessary to consider what principles there are in the law, as part of determining what the existing law is, as Dworkin argued. It is not possible to separate out the determination of the law in the light of previous decisions from the exercise of moral judgement to make new law.

A similar objection made against Dworkin is that, even if we accept that judges formulate principles by drawing on previous decisions in combination with the exercise of moral judgement, it does not follow that these principles are part of the law. This could be the way that judges make new law under the individual rule approach. According to Marmor, ${ }^{29}$ the only reason Dworkin gives

\footnotetext{
${ }^{26}$ Thus, as Dworkin argued, legal principles cannot be identified by a complex test consistent with the sources thesis: Dworkin, above n20, at 39-45 and 64-8.

${ }^{27}$ Raz, above n5, at 46.

${ }^{28}$ Raz, ibid; Marmor, above n11, at 89; David O Brink, "Legal Theory, Legal Interpretation, and Judicial Review" 17 Philosophy and Public Affairs 105 at 110 (1988).

${ }^{29}$ Marmor, above n11, 89-92. It is not relevant here to consider the objection to Dworkin's approach that it pays insufficient heed to the wording of statutory or constitutional provisions: see for example Alexander, above n19.
} 
Author: Peter Jaffey, University of Leicester

for thinking that principles identified in this way are already part of the law is "judicial rhetoric". But under the holistic approach this exercise is necessarily part of determining the existing law, and not a matter of rhetoric. In the nature of the holistic approach, it is not possible to identify the existing law without it. Possibly it is consistent with the individual rule approach for judges to use this approach to gap-filling, though the individual rule approach does not require it, and indeed as considered below it seems to be generally considered a strength of the individual rule approach that where there is a gap it requires the judge to formulate a rule on the basis of what he considers to be the relevant moral principle rather than a principle constructed in this way.

More generally, whereas the individual rule approach implies that the law consists of a determinate number of rules, and excludes principles, the holistic approach represents the law as an account of justice consistent with previous decisions, so that previous decisions do not generate a determinate set of elements at all, whether rules or principles. It might be better to think of it as a process of legal reasoning to determine the law, which draws on previous decisions as constraints and is for the time being expressed in terms of provisional rules. ${ }^{30}$

\section{MAKING NEW RULES: ANALOGICAL REASONING AND COHERENCE}

Analogical reasoning is widely recognised as an important part of common law legal reasoning,

though it is controversial how exactly it should be understood and indeed whether there is a rational basis for it. ${ }^{31}$ On the individual rule approach, legal reasoning has two distinct stages. The first stage involves the application of rules laid down in previous cases to facts that fall under them. The second stage involves devising new rules to deal with facts that fall in a gap between existing rules, where no existing rule applies, and analogical reasoning is understood as a method or technique of moral reasoning for devising new rules. More particularly, it involves extending a rule previously laid down into a gap, as it were, so that it applies to the facts of the case now in issue, on the ground that these

\footnotetext{
30 See Dworkin, above n13, 234.

${ }^{31}$ See generally, for example, Raz, above n5, ch 10; Neil MacCormick, Legal Reasoning and Legal Theory (Oxford: OUP, rev edn 1994), ch 7; Cass R Sunstein, Legal Reasoning and Political Conflict (Oxford: OUP, 1996), ch 3; Lloyd L Weinreb, Legal Reason (Cambridge: CUP, 2005); GJ Postema, “A Similibus ad Similia: Analogical Thinking in Law," in Edlin, above n9.
} 
Author: Peter Jaffey, University of Leicester

facts are analogous to - in relevant respects the same as - the facts of cases that fall under the existing rule, and so the case should be decided in the same way. ${ }^{32}$

This is not understood as a matter of reasoning from precedent, since it does not involve applying a rule laid down in a previous decision. ${ }^{33}$ When the court in the previous case formulated a rule to lay down, it decided that circumstances covered by the rule are analogous to each other, and this decision does not provide any support for extending the rule further by treating other possible cases as analogous. The new court may decide that the rule should be extended, but this must be based on a new judgement of the appropriate rule for the circumstances, to which the previous decision is not relevant. Thus critics of analogical reasoning say that all it does is provide a spurious appearance of reasoning or "window dressing" for new rules for which no genuine reasoning is actually offered. Possibly the best that can be said for analogical reasoning, as it operates under the individual rule approach, is that it is a technique under which a previous decision provides a starting point for the formulation of a new rule, which is at least likely to promote continuity and predictability in the development of the law. ${ }^{34}$

On the holistic approach, the task of the new court is to determine the appropriate rule to govern the old case and the new one. In other words, it has to decide what sorts of case are analogous to the previous case in order to formulate a rule. It could extend a rule previously stated so that it applies to the new case, on the basis that the new case is analogous to the old one, or it could distinguish a previous case that ostensibly applies and qualify the rule so that it does not apply, on the ground that they are not analogous. Analogical reasoning is part of the exercise of formulating the rule for which the previous case is taken to stand. It is part of reasoning from precedent, rather than being distinct from it. Under the holistic approach, the court takes previous decisions to be morally correct on their facts, and it does seem to be a valid form of reasoning for a

\footnotetext{
32 e.g., Hart, above n9, in the postscript, at 274-5; Raz, above n5, at 201-6.

${ }^{33}$ e.g. Schauer, above $\mathrm{n} 1$, distinguishes between precedent and analogy.

${ }^{34}$ Alexander \& Sherwin, above n7, at 86-7; Raz, above n5, at 205-6.
} 
Author: Peter Jaffey, University of Leicester

court to make a decision in a way that it considers makes it consistent with a previous decision that it takes to be correct.

More fully, analogical reasoning under the holistic approach is a part of the construction of a body of rules to account for previous cases. The assumption behind the holistic approach is that a judge in an individual case is generally likely to reach the right outcome on the particular facts, but may not formulate the right rule to apply to other cases as well, and that the best set of rules will be reached by considering many decisions in varying circumstances, and identifying genuine distinctions and avoiding contrived or spurious distinctions in formulating a body of rules, which one might say involves multiple analogies working together, or, in other words, coherence reasoning. At the same time, judges can identify moral principles that support previous decisions, i.e. legal principles, in support of possible rules. Furthermore, as mentioned earlier, the holistic approach allows for theoretical ascent, increasing generality and abstraction in moral theorising over the construction of rules, which amounts to seeking coherence over a wider field of law and searching for corresponding legal principles. By contrast, on the individual rule approach, the assumption is that the best body of rules is likely to be reached by allowing each court to consider carefully a particular set of facts and to lay down a rule to govern that situation, and then taking these rules as conclusive and aggregating them to form the law, without any attempt at mutual reconciliation through coherence reasoning or theoretical ascent.

Thus under the holistic approach analogical and coherence reasoning are part of the process by which the courts aim to construct a body of rules that bring moral principles and previous decisions into harmony. If courts have reasonably sound but not infallible moral judgement, and judgements on particular facts ought to be justifiable by reference to moral principles, and different courts exercise independent judgement, it seems reasonable to think that the way judgements are combined under the holistic approach has a synergistic effect in developing just rules that is not available under the individual rule approach. Theoretical ascent strengthens the holistic approach because it increases the scope for mutual support across a range of decisions. 
Author: Peter Jaffey, University of Leicester

Various objections might be made to the holistic approach and coherence reasoning. ${ }^{35}$ One objection is that it is incompatible with the basic idea of the common law as law generated by authoritative precedents. The starting point for this argument is that the reason why previous decisions are authoritative is that judges are, by virtue of their expertise, in a position to make just decisions and this is why their decisions should be deferred to and treated as authoritative. This at least is the assumption made by the law and one should understand the law on this basis. ${ }^{36}$ It would then appear to follow that a previous decision can be authoritative as a precedent only if its effect in making law is ascertainable without the exercise of moral judgement. It would be incoherent, it would seem, for a court (or someone subject to the law) to be required to respect a previous decision on the ground of the judge's sound moral judgement, but then to be required to exercise moral judgement in order to establish what the decision is, that is to say its effect in making law, because one cannot at the same time both defer to the judge's moral judgement and exercise one's own moral judgement on the same question. If a decision can be authoritative only if its effect can be determined without the exercise of moral judgement, it seems that it must be understood to lay

\footnotetext{
35 The holistic approach has something in common with the reflective equilibrium method of personal moral reasoning, according to which, by reflection on one's moral judgements about what is required in particular situations, and about the relevant moral principles, and by trying to bring them into harmony with each other, one is likely to discern which judgements are mistaken and thereby reach sounder judgements. The method is attributed to J Rawls, $A$ Theory of Justice, rev edn (Cambridge, Mass: Belknap Press, 1999) at 42-3. See Dworkin, above n13, 251; Law's Empire, above n4, 276-312; Michael S Moore, "Precedent, Induction, and Ethical Generalisation” in Laurence Goldstein, ed, Precedent in Law (Clarendon Press, 1987). According to Alexander \& Sherwin, above $n 7,93-4$, the analogy with reflective equilibrium method is misconceived because in the common law previous decisions are not open to revision. Under the individual rule approach, there is no basis for modifying a rule previously laid down for the sake of promoting overall coherence, and overruling calls for a special power to expunge a decision from the law on the ground that taken in isolation it is obviously wrong, but under the holistic approach a previous decision can be varied, at least in the sense that it is open to a judge to determine which facts of a previous decision are relevant and so change the ratio of the case, and furthermore overruling of previous decisions has a natural place in coherence reasoning, that is to say where the decision has been exposed as mistaken in the light of other decisions and the legal principles that support them. Another objection is that the holistic approach in the common law is not a method of personal moral reasoning: Alexander \& Sherwin, ibid. A judge following the holistic approach, although exercising moral judgement himself, may be constrained in the end to make a decision that does not coincide with his own overall moral judgement. But this does seem quite feasible. In analogical reasoning, a judge can hold that there is no material moral difference between two cases without necessarily thinking that the previous decision was correct, and a judge can consider that although he prefers one principle another one has stronger support in the cases.

${ }^{36}$ See Alexander \& Sherwin, above n7, ch II. According to Joseph Raz, the law is not necessarily a genuine moral authority, but by its own lights it is, that is to say it always claims to be or purports to be a moral authority, and to understand the law we should treat it on its own terms as a moral authority: Raz, above n5, ch3. Under Raz's "service conception" theory of authority, a moral authority is, vis-à-vis a subject of the authority, a body whose directions the subject ought to follow because by doing so the subject is more likely to act as he ought to, which is generally because the authority is in a position to determine what the subject ought to do more reliably than the subject can do for himself (the "normal justification thesis"): Raz, above n5, ch1; Joseph Raz, The Morality of Freedom (Clarendon Press, OUP, 1986), ch 3; Ethics in the Public Domain (Clarendon Press, Oxford, 1994), Ch 10.
} 
Author: Peter Jaffey, University of Leicester

down a rule that identifies a category of factual situations for which the law specifies a legal consequence, as the individual rule approach prescribes. The holistic approach is ruled out because under it the effect of a precedent is a matter for moral judgement exercised through analogical and coherence reasoning. The implication seems to be that there cannot be any basis for treating the constraints generated by the holistic approach as authoritative with respect to justice, or in other words that it cannot be justified to use the holistic approach as a method for developing a just body of rules. ${ }^{37}$

This conclusion may be true in some circumstances, ${ }^{38}$ but with respect to the common law it is difficult to see how this argument from authority can show that the holistic approach is misconceived as a method for arriving at a just body of rules, or that it is a worse method than the individual rule approach. Like the individual rule approach, the holistic approach works on the assumption that previous decisions were soundly made, though in a different sense. It requires individual decisions to be taken into account and reconciled with each other through coherence reasoning, and it implies that precedents are authoritative, not individually but collectively. In effect, the holistic approach treats the law as a whole as a single authority, whereas the individual rule approach treats each court, when it makes a decision, as a distinct, independent authority. ${ }^{39}$ Another objection to coherence reasoning under the holistic approach is that the law should be intended to achieve justice, but, it is said, the holistic approach treats coherence in the law as

\footnotetext{
${ }^{37}$ This is the core of Raz's argument for legal positivism and the "sources thesis", the theory that the law by its nature is such that it is possible to state it without any exercise of moral judgement: Raz, ibid. As Shapiro makes the point, "Having to answer a series of moral questions is precisely the disease that the law aims to cure": Scott J Shapiro, Legality (Cambridge, Mass: Belknap Press, HUP, 2011) at --. On Dworkin's approach, a judge can follow a precedent and exercise moral judgement at the same time: Dworkin, above n13, at 208. See also Jeremy Waldron, "Legislators' Intention and Unintentional Legislation", in Andrei Marmor, ed, Law and Interpretation (Oxford: Clarendon Press, 1995).

${ }^{38} \mathrm{~A}$ distinction is made below at $\mathrm{n} 52$ between legislative authority and the authority of courts to make new rules.

39 On this understanding, although the holistic approach is not consistent with the sources thesis, it is consistent with the service conception theory of authority because by following the holistic approach the judges are more likely to achieve a just outcome than by exercising judgement without reference to other cases: see above n36. Dworkin rejected Raz's theory of authority: Dworkin, above n13, at 198-211. However, it is not clear, on Dworkin's approach, what understanding of authority is relied on to establish that previous decisions should be followed at all. Hershovitz points out that there is no reason why the decision of a court should in general have authority over a later court under the normal justification thesis: Scott Hershovitz, "Integrity and Stare Decisis", in Scott Hershovitz, ed., Exploring Law's Empire (Oxford: OUP, 2006) at 108. The decisions of the courts taken together under the holistic approach might well be understood to have authority over later courts under the normal justification thesis.
} 
Author: Peter Jaffey, University of Leicester

independently valuable, and therefore compromises on justice in the interests of coherence. ${ }^{40} \mathrm{By}$ contrast, it might seem that the individual rule approach is aimed purely at justice because this must be the objective of each decision considered on its own. Dworkin's approach to coherence gave some support to this objection. He thought that the justification for promoting coherence in the law lay not in justice and the development of just rules, but in a distinct and potentially competing value in the law, namely "integrity". ${ }^{41}$ This seems to be the elaboration of a similar understanding of analogical reasoning. It is sometimes said that the basis for analogical reasoning is that the current case and the previous case should be treated in the same way because it would be unfair to the parties to the current case (or one of them) if it were decided differently. In other words, it is based on a principle of fairness or equal treatment with respect to equivalent cases..$^{42}$ On this understanding, it is not relevant to the current decision whether the previous decision is, or is presumed to be, a morally sound decision. If this were the right way to understand analogical reasoning, the implication would be that it gives rise to a conflict in the law between fairness or equal treatment as between cases, on the one hand, and justice, on the other hand, and it would have the effect of promoting coherence for its own sake rather than in the interests of justice..$^{43}$ This understanding of analogical reasoning may be appropriate to the individual rule approach, which treats analogical reasoning as quite separate from precedential reasoning, but it is not how analogical reasoning or coherence reasoning should be understood under the holistic approach. The holistic approach is not based on the intrinsic value of equal treatment or coherence. Its rationale is that it leads to just decisions and the development of a just body of rules based on the assumption that previous decisions are generally morally sound.

\footnotetext{
${ }^{40}$ See e.g. Joseph Raz, "The Relevance of Coherence" 72 Boston University Law Review 273 (1992); Christopher J Peters, "Foolish Consistency: on Equality, Integrity, and Justice in Stare Decisis" 105 Yale Law Journal 2031 (1996). Lawrence G Sager, above, n17 at 120, refers to "structuring principles" that make the law sub-optimal. For more sympathetic accounts of Dworkin's theory of integrity, see Gerald J Postema, "Integrity: Justice in Workclothes", Ch 16 of Justine Burley, ed., Dworkin and his Critics (Malden and Oxford: Wiley-Blackwell, 2004); Hershovitz above n39, 114-5.

${ }^{41}$ Dworkin, Law's Empire, above n4, ch6.

42 This approach seems to have been adopted by Dworkin at one time: Dworkin, above n20, at 113 . See also Michael S Moore, "Legal Principles Revisited", 82 lowa Law Review 867 at 872 (1997).

${ }^{43}$ See Alexander \& Sherwin, above n7, at 37-9 and 66-88.
} 
Author: Peter Jaffey, University of Leicester

The same argument is also made against legal principles under the holistic approach. It is said that if the court is not bound by a previous rule and has to exercise moral judgement to make a new rule, it ought to try and identify the true moral principle that applies in the circumstances rather than applying a legal principle. The true moral principle will lead to a just decision, whereas relying on a legal principle, which is established by looking for support from a range of decisions, is liable to lead the court away from a just outcome for the sake of coherence ${ }^{44}$ But under the holistic approach a legal principle is a moral principle identified under the holistic approach, as opposed to a moral principle determined as such by the free exercise of judgement by a judge, and the assumption is that a legal principle, having support from a range of decisions, is more likely to be a sound moral principle than a principle identified in isolation by a judge without the benefit of the holistic approach. Of course, under the holistic approach the law may go astray under the influence of bad decisions, but when this happens the problem is not that the holistic approach recognises legal principles or analogical or coherence reasoning, but that judges are bound to take bad decisions into account, and of course the problem of bad decisions arises under the individual rule approach as well, and indeed is more difficult to overcome.

It might also be said against the holistic approach that, since rules are provisional, and the determination of the law may depend on an exercise of moral judgement, what is taken to be settled law may not in fact be the law at all, and it seems counter-intuitive that the law could be like this. Surely it is in the nature of law that we should generally be able to establish the legal position definitively, even if it is sometimes unknown or uncertain? ${ }^{45}$ But there is no suggestion that under the holistic approach decisions already made by the courts can be set aside and re-litigated, on the ground that they were decided on a mistaken understanding of the law. Although on the holistic

\footnotetext{
44 See generally Alexander \& Sherwin, above n7, at 88-103; Larry Alexander \& Ken Kress, "Against Legal Principles" in Andrei Marmor, ed, Law and Interpretation (OUP, 1995), at 293-4. In support of legal principles, see Jeremy Waldron, "The Need for Legal Principles" 82 lowa Law Review 857 (1997); Stephen R Perry, "Two Models of Principles" 82 lowa Law Review 787 (1997).

${ }^{45}$ Alexander \& Sherwin, above n7, at 88-103; Leiter, above n16; Marmor, above n11, 90-92. See also Kenneth Einar Himma, "Immodesty in Dworkin's Theory: The Lines Dividing Different Kinds of Conceptual Theory of Law" in W Waluchow \& S Sciaraffa, above n17.
} 
Author: Peter Jaffey, University of Leicester

approach one would say that our understanding of the law has changed since the decision was made, and on the individual rule approach that the law itself has changed since it was made, there is no practical difference between the two approaches with respect to the finality of previous decisions as between the parties, or as to settlements made on the basis of the law as it was understood at the time ${ }^{46}$ Thus this is not an objection of impracticality, as it might appear to be. Furthermore, even if it is counter-intuitive in this respect, as considered above the holistic approach provides a good account of ordinary legal reasoning, whereas the individual rule approach, though it may not be counter-intuitive in this respect, cannot adequately account for ordinary legal reasoning.

There is a related objection, finally, that the line of argument above is misconceived because justice in the law truly consists only in applying binding rules previously laid down, as the individual rule approach holds, so that people are judged against definitive rules that they can be taken to know, which provide guidance to them, in accordance with the standard requirement of the rule of law. ${ }^{47}$ On this view of the law and of the court's function, it would seem that certainty is paramount. The objective of the holistic approach is to find a just solution on the facts, previous decisions contributing not by providing binding rules that determine the position definitively when they apply, but by being factored into the process of determining what rule would be just in the circumstances, in the absence of a binding rule. It would appear that the holistic approach is open to the objection that it is lacking in certainty because it generates only provisional rules. ${ }^{48}$ However, with respect to guidance the individual rule approach also has weaknesses. The rules of the common law are not comprehensive, and so the outcome of litigation will in any case not always be ascertainable by

\footnotetext{
${ }^{46}$ There is a difference with respect to the case where $C$ made a payment to $D$ on the basis of an assumption about the legal position consistent with the current understanding of the law, but inconsistent with what the court now determines is the legal position. According to Kleinwort Benson v Lincoln City Council [1998] 3 WLR 1095, the payment will be recoverable as a mistaken payment, which is consistent with the declaratory theory and the holistic approach but not the individual rule approach. See further Finnis, above n19.

${ }^{47}$ Associated in particular with the account in Lon Fuller, The Morality of Law (Yale UP, 1964).

${ }^{48}$ Alexander \& Sherwin doubt whether, if the law incorporates legal principles, it constrains later courts at all: above $n 7$ at 88-94. They assume that a precedent can create a constraint only by way of a rule that dictates the outcome of subsequent cases falling under it, as under the individual rule approach. On their view, ibid at 97 , a legal principle could be any moral principle a court chose, modified to incorporate arbitrary exceptions to achieve consistency with any previous decisions that are at odds with the principle, but this is a rule rather than a principle in the sense suggested above, and indeed involves the sort of incoherence that the holistic approach would aim to exclude.
} 
Author: Peter Jaffey, University of Leicester

reference to existing rules (and even where a rule previously laid down is applicable, there is likely to be a power to override it). In addition, so far as guidance is concerned, rules are not promulgated by the courts in the same way as for a legislative enactment; they are not public and accessible in the same way. Conversely, under the holistic approach there is no reason to think that the law cannot generally become settled, even if the rules are actually provisional. Furthermore, if, as suggested above, the holistic approach is a superior method for making just decisions and therefore for developing a just body of rules, in this sense it provides superior guidance even if it is less certain.

An additional weakness of the individual rule approach is that, because the law is built up one rule at a time without any room for reorganisation or revision, and without the benefit of theoretical ascent, one would think that it might tend to accumulate mistakes and to become unduly complicated and opaque and generally to show an "hostility to abstract order". ${ }^{49}$ This criticism is often made of parts of the common law, and, where the criticism is justified, it seems that the source of the problem must be the influence of the individual rule approach. By contrast, as discussed above, by drawing on the cases collectively and in the light of underlying principle, the holistic approach would be expected to make the law more coherent and the rationale for its doctrines more visible, and the law should generally be clearer. Again this is an aspect of guidance, though it is not a matter of certainty.

Thus, with respect to the rule of law, if this is just a matter of whether there are binding rules to apply, and certainty is the only consideration, the individual rule approach may be preferable (though this is not clearly the case), but the holistic approach comes out of the comparison much better if considerations of justice and clarity are also taken into account.

\footnotetext{
49 Bernard Rudden, "Torticles" 6/7 Tulane Civil Law Forum 105 (1991-92); see also Stephen Waddams, Dimensions of Private Law (Cambridge: CUP, 2003), ch 1.
} 
Author: Peter Jaffey, University of Leicester

\section{MAKING NEW RULES: HOW THE COURTS ARE CONSTRAINED}

\section{The standpoint constraint on developing the law in adjudication}

There is a further aspect to the rule of law which favours the holistic approach. There is an important constraint on the courts' freedom to make new rules under holistic approach, which I will refer to as the "standpoint constraint". I will first explain the standpoint constraint without reference to the two approaches to precedent.

Imagine a situation in which there is no rule about which side of the road cars should be driven, and there is a collision between two cars being driven in opposite directions on the same side of the road. Could a court hold one of the drivers liable to the other on the basis of a rule laid down in the adjudication, to the effect that cars must keep to the left? One might object, first, that this would not comply with the standard rule of law requirement for a rule to be pronounced in advance of its application, but this cannot always be avoided in the common law, since the common law is bound to involve the application of new rules. However, there is an additional objection to the application of this new rule. Let us say that, instead, the court decides the case by applying a rule that drivers should take reasonable care, no such rule having previously been laid down. This would also be contrary to the standard rule of law requirement, but it would appear to be acceptable in a way that applying the "drive on the left" rule would not.

With respect to the "drive on the left" rule, although it may be clear that it would be desirable to introduce a convention to co-ordinate people's behaviour for the good of all, it is unfair to adjudicate on a dispute between two parties on the basis that the convention has already been introduced if it has not, because of the arbitrary element to a convention which means that it cannot be anticipated. No-one can have a moral duty to drive on the left or legitimately bear the risk of failing to do so before he knows or ought to know that this convention has become established. More generally, this suggests that a new rule introduced by a court in adjudication should be justifiable by reference to what the parties know or can be taken to know about their circumstances and about the consequences of their conduct for others, as is the case for the reasonable care rule. 
Author: Peter Jaffey, University of Leicester

Thus it would appear that we should distinguish between two ways of making new rules.

First, one can simply determine the best rule for the future, as a matter of justice, all things considered, taking account of the interests of individuals and the public interest, and taking account of any information that is available about the possible effects of the rule. This is certainly what a legislature should do. The rule takes effect prospectively and, in accordance with the standard rule of law principle, people are judged according to a rule already laid down that they ought to have been aware of and followed. Secondly, one can make a new rule, again aimed to achieve justice, taking account of the interests of individuals and the common good, but here taking into account only what is known or can be taken to be known to people to whom the rule will apply, in other words, as I will say, from their standpoint..$^{50}$ This approach is appropriate for a court laying down a new rule in adjudication, where the new rule is also the rule that resolves a dispute that has arisen over events that have already occurred. This is the standpoint constraint on rules that are laid down in adjudication. It precludes a court from laying down a rule that is conventional or arbitrary or whose justification depends on specialist or expert knowledge. ${ }^{51}$

According to Joseph Raz, the usual reasons for accepting that a body (including a court) has authority are that it is in a position to lay down co-ordinating conventions, and that it has access to expert knowledge; ${ }^{52}$ without these, it would normally be in the same position as an ordinary subject of the law and, according to Raz, there would be no reason to defer to its judgement in preference to that of the ordinary subject, and so no reason to recognise its authority to make rules. On this view, for a court to have authority to create a precedent it must be a legislative authority, capable of making rules from a superior standpoint to that of ordinary people, unconstrained by their limitation

\footnotetext{
${ }^{50} \mathrm{Cf}$ the "rights conception" of the rule of law in Ronald Dworkin, "Political Judges and the Rule of Law" In A Matter of Principle (Oxford: Clarendon Press, 1986). As to the failure of the common law to satisfy the standard requirement of the rule of law, see Benjamin C Zipursky, "The Inner Morality of Private Law" 58 Am Journal of Jurisprudence 27 (2013), and "Torts and the Rule of Law" in Lisa M Austin \& Dennis Klimchuk, eds, Private Law and the Rule of Law (OUP, 2014). ${ }^{51}$ This is not intended to imply "standpoint theory" in the sense of relativity of knowledge according to standpoint.

52 In accordance with the normal justification thesis: see above n36. Otherwise the authority adds nothing to what the subject can determine for himself: this is the "no-difference" theory. I am disregarding the possibility of authority other than under the normal justification thesis.
} 
Author: Peter Jaffey, University of Leicester

in knowledge. ${ }^{53}$ However, under the standpoint constraint, a common law court is not a legislative authority, but an authority with respect to justice in adjudication, which means to say that its competence is in discerning what is just on the basis of the same information that is available to ordinary people, from their standpoint. ${ }^{54}$

The standpoint constraint is, in effect, a distinct rule of law principle relevant to the common law. The effect of the constraint is that, although the dispute is resolved by a new rule that applies retrospectively, contrary to the standard rule of law principle, it is at least a rule that could have been anticipated by the parties, which parties with good moral judgement would have expected, because it must be justifiable on the basis of what they can be taken to know. ${ }^{55}$ To put it another way, the new rule must be intended to reflect the existing moral rights and duties of the parties, on the assumption that these depend on what they know or ought to know.

Under the standpoint constraint, various types of new rule that are open to a legislature legislating for the future are beyond the competence of a court introducing a new rule in adjudication. A court cannot introduce a convention, as in the example given requiring drivers to keep to the left, though it could adopt a convention that has already arisen spontaneously. Similarly, a court cannot introduce precise limits, caps, qualifications or formalities, all of which have a conventional or arbitrary element. A court cannot draw on esoteric information that is not generally available, so it cannot, for example, introduce a regime of detailed regulation of behaviour based on expert knowledge, in place of a requirement of reasonable care. More generally, a court cannot

\footnotetext{
53 The issue here is not whether the authority is actually a genuine moral authority, which actually meets the requirements of the normal justification thesis, but what sort of authority it claims to have.

${ }^{54}$ Possibly one can make this distinction by saying that the common law has theoretical rather than practical authority: see Jaffey above at $\mathrm{n} 2$.

55 According to Kenneth Kress, on Dworkin's theory decisions are liable to have a retrospective effect because a decision may affect the way in which a later court will determine the law, even with respect to events before the decision, by influencing what principles the case law supports, and so Dworkin's theory falls short of its own claim to avoid retrospectivity: Kenneth J Kress, "Legal Reasoning and Coherence Theories: Dworkin's Rights Thesis, Retroactivity, and the Linear Order of Decisions" 72 California Law Review 369 (1984). See also Alexander \& Sherwin, above n7, 101-2; Alexander \& Kress, above $n 44,296-7$. Under the holistic approach a decision can have this effect, though given the provisionality of rules it is not clear that this would actually amount to a retrospective change in the law. In any case the holistic approach generally avoids retrospectivity, as compared to the individual rule approach, because (i) rules are provisional and so allow for distinguishing and (ii) decisions are made according to the standpoint constraint. Under the holistic approach the objection is really uncertainty rather than retrospectivity.
} 
Author: Peter Jaffey, University of Leicester

introduce a regulatory regime of rules designed to organise people's behaviour in a way that requires them to act in a way that they could not have anticipated would be required of them, because it draws on expert knowledge and has arbitrary elements, such as a road traffic scheme that would benefit all drivers but could not be anticipated from the drivers' standpoint. Similarly, a court could not introduce limited liability for investors in a commercial project, in adjudication of an action by a creditor. A rule introduced to govern the legal position as between the creditor and the investors must depend on the circumstances as they were apparent to investors and creditors at the time when the creditor engaged with the business, which would mean the facts concerning the particular business and the individuals involved. Whether limited liability should be introduced (to promote investment in business) depends on facts about the economy as a whole, which are apparent to the legislature but not to the parties from their standpoint. More generally, with respect to contract, although a court can adopt a rule that invalidates a contract on the ground of public policy or illegality, for example a contract to carry out a theft or to evade tax, where the grounds for invalidity arise from facts known to the parties, it cannot adopt a rule that invalidates contractual provisions in order to avoid more indirect and diffuse effects of contracting on third parties or the community as a whole, for example environmental damage or the exploitation of workers, as a legislature could do with prospective effect.

More generally, in private law a court is largely confined to developing and applying rules based on the facts apparent to individuals with respect to other individuals with whom they may interact through an accident or an exchange or transfer, which means relying on bilateral principles that apply as between individuals (modified to take account of particular third party interests or particular aspects of the public interest discernible from the parties' standpoint), and not rules that are designed to advance aggregate welfare across the society, which are liable to depend on facts that are not accessible to the parties. Furthermore, since the court has to consider what is apparent to the parties in advance of any particular interaction, it is bound to construct the law on the basis of appropriate assumptions about other people in general, such as assumptions of reasonableness or 
Author: Peter Jaffey, University of Leicester

equality. Thus the standpoint constraint provides an explanation for the general character of private law. ${ }^{56}$

In some cases where a possible rule is beyond the court's competence, the court may lack the expertise necessary to work out what rule would be best, or it may lack the executive authority required to implement the rule, for example for establishing a register, but the fundamental limitation is that the court cannot introduce a rule in adjudication which is not justifiable from the parties' standpoint, by reference to the facts that the parties can be taken to know, because this would be unjust to them (or to other people with respect to events that have already happened).

One might object that the standpoint constraint is mistaken in treating the justice of the position as between individuals, which determines the outcome in adjudication, as depending on the facts accessible to people in their position, as opposed to what we might say are the true facts, whether known or accessible to them or not. One might think that, in making a new rule, the court should determine what is morally required, all things considered, and so take account of all the relevant facts, whether the parties were or could have been aware of them or not. Some commentators do insist that someone's moral rights or duties do always depends on the actual facts, independent of what is or ought to be known to that person, rather than the facts apparent to or accessible to them. One example discussed is the case where D presses a switch intending to turn on a light and not knowing that the switch has been wired to cause an electric shock to ${ }^{5}{ }^{57}$ Should one say that $D$ has a duty not to press the switch, or would he have such a duty only if he knew or ought to have known of the consequences of pressing the switch? One might think that both usages have their place.$^{58}$ Where the issue is how to evaluate D's conduct, to establish whether to hold D liable to $C$, in the light of how D has acted vis-à-vis $C$, it is surely right to take account only of the apparent or accessible facts. ${ }^{59}$ By contrast, in making a rule for the future, to provide guidance for this

\footnotetext{
56 i.e. its bilateral and objective character, which is often attributed to its basis in corrective or commutative justice.

57 Judith Thomson, The Realm of Rights (Harv UP, 1990), 229.

58 See Derek Parfit, On What Matters, Vol 1 (OUP, 2011), 150-51.

59 TM Scanlan, Moral Dimensions (Harv UP), 47-52.
} 
Author: Peter Jaffey, University of Leicester

situation for the future, but not to determine liability with respect to previous events, it would be appropriate to take account of everything that can be known to the rule-maker about the situation.

When a court makes a new rule, because it has to be a rule that deals justly with the dispute, as well as operating for the future, it should consider only the facts apparent or accessible to the parties, whereas a legislature legislating for the future should lay down the best rule in the light of all the facts known to it.

Retrospectivity is an unavoidable part of the common law, because the courts are bound to make new rules and apply them to events that have already occurred, but where the standpoint constraint is respected one can say that the new rule is not unfairly retrospective, because it is consistent with what the parties ought to have done or what risk they properly bore, in the light of what they can be taken to know about the circumstances and the consequences of their actions. It is said that in the common law, where retrospectivity cannot be avoided, a new rule is objectionable only when it fails to respect expectations that the law has previously generated, that is to say where a rule previously laid down (and understood to constitute the law) is disapplied and a different rule applied. ${ }^{60}$ However, the examples given above, such as the "drive on the left" example, show that this is not the case. Although retrospectivity is unavoidable, a rule is unfairly retrospective, even if it does not contradict expectations engendered by previous decisions, if it is not devised from the parties' standpoint and intended to reflect their existing moral rights.

The suggested distinction between the two approaches to rule-making plays the role in the common law that Dworkin attributed to his distinction between principle and policy: he argued that, in developing the common law in adjudication, the courts are confined to arguments of principle, whereas the legislature can make law based on policy as well. Thus one might say that the suggested distinction, based on the standpoint constraint, is a version of the principle/policy distinction.

\footnotetext{
60 See Hart, above n9, in the postscript at 276; Raz, above n5, at 197-8; Kenneth J Kress, "Legal Reasoning and Coherence Theories: Dworkin's Rights Thesis, Retroactivity, and the Linear Order of Decisions" 72 California Law Review 369 (1984), 389. Endicott argues that there can be no objection to applying a new rule if it is introduced into the law in accordance with appropriate standards of law-making, consistent with the rule of law: Timothy Endicott, "Adjudication and the Law" (2007) 27 OJLS 311. The argument in the text is that introducing new rules on the basis of arguments of policy does offend against these standards.
} 
Author: Peter Jaffey, University of Leicester

However, these expressions are used inconsistently. "Policy" or "legal policy" is sometimes used in a broad sense to refer to any consideration taken into account in the formulation of new rules. But if policy arguments are understood more narrowly as arguments concerned with the promotion of the public interest or the interest of a section of the public or with distributive justice, the standpoint constraint does put policy arguments largely, though not entirely, beyond the reach of the courts, because policy arguments are largely invisible from the parties' standpoint, in the sense that the facts to support them are not accessible. ${ }^{61}$

\section{The standpoint constraint and the two approaches to precedent}

For the purposes of analogical reasoning one is bound to assume a common standpoint. If one infers

from the equivalence of the sets of facts in the two cases that they should be decided in the same way, one necessarily assumes that in the two cases the facts have the same significance to the parties, which means that they are taken to have the same background knowledge relevant to the facts. The same is true for coherence reasoning in the sense suggested earlier, and more generally for the holistic approach. When a court formulates a rule on the holistic approach, it must be a rule that is consistent with previous decisions in the sense that they could have been decided by applying the rule. This approach is only possible if all decisions are taken and interpreted from the same standpoint, which must be the common standpoint of ordinary people, that is to say on the basis of what the ordinary person can be taken to know and be capable of doing. The holistic approach thus necessarily applies the standpoint constraint to the making of new rules. It necessarily precludes the court from introducing a new convention or relying on specialist information. It aims to generate rules that reflect the parties' existing rights, and so avoids new rules that are unfairly retrospective

\footnotetext{
${ }^{61}$ See Dworkin, above n20, at 22-28 and 90-100. A distinction along the lines of Dworkin's policy/principle distinction is widely recognised and discussed: see, for example, Darryn Jensen, "Theories, Principles, Policies and Common Law Adjudication" (2011) 36 Australian Journal of Legal Philosophy 34; D Kyritsis, "Principles, Policies and the Power of Courts" (2007) 20 Canadian Journal of Law and Jurisprudence 379. See also Weinrib, above n4, 69-79, on "two notions of policy". Dworkin's distinction has of course often been criticised: see for example Kent Greenawalt, "Policy, Rights, and Judicial Process" in M Cohen, ed, Ronald Dworkin and Contemporary Jurisprudence (London: Duckworth, 1984); John Bell, Policy Arguments in Judicial Decisions (Oxford: Clarendon Press, 1983); MacCormick, above n17. Leiter rejects the distinction out of hand: see Brian Leiter, "The End of Empire: Dworkin and Jurisprudence in the 21 $1^{\text {st }}$ Century" 36 Rutgers Law Journal 165 (2004). See also J Stapleton "The Golden Thread at the Heart of Tort Law: Protection of the Vulnerable" (2003) 24 Australian Bar Review 135.
} 
Author: Peter Jaffey, University of Leicester

in the sense explained above. ${ }^{62}$ One might think that the idea of the common standpoint of ordinary people or ordinary common knowledge is not precise or well defined, but for present purposes it is enough to point out that it is in any case generally assumed in analogical reasoning and coherence reasoning.

As mentioned above, under the individual rule approach the declaratory theory is understood to hold that the law consists of a complete body of fixed, binding rules, which cannot be the case, which is why the declaratory theory is often taken to be a myth. The holistic approach does conform to the declaratory theory, though it does not understand the declaratory theory in this way. The holistic approach conforms to the declaratory theory because on the holistic approach the law is constructed to conform to previous decisions and the existing law cannot be identified except in the process of determining what the law is on the facts in dispute. As mentioned above, this might be thought to give effect to the declaratory theory in only an illusory way, but to the contrary, by virtue of the standpoint limitation, under the holistic approach the common law does in a certain sense genuinely conform to the declaratory theory and not operate retrospectively.

If instead the courts employed the individual rule approach, it would still be possible for them to limit themselves to making new rules subject to the standpoint constraint, but it would not be a natural or inherent constraint, as it is under the holistic approach. Under the individual rule approach it might seem appropriate for the court simply to devise the best rule for the future, all things considered, free of the standpoint constraint, just as a legislature would, the concern being purely to provide guidance for the future. This is in fact how the individual rule approach has been understood by its proponents, ${ }^{63}$ and on this understanding retrospective law-making in the objectionable sense seems natural and unavoidable.

One of the puzzles of the common law is that it might seem that one must either be a formalist, holding that the law consists of a fixed and comprehensive body of rules, or instead one is

\footnotetext{
${ }^{62} \mathrm{Cf}$ Dworkin, above n20, at 113, where he says that a decision justified on the grounds of policy would have no "gravitational force".

${ }^{63}$ See generally Joseph Raz, "Facing Up: A Reply" 12 Southern California Law Review 1153 (1989).
} 
Author: Peter Jaffey, University of Leicester

bound to accept that, since judges exercise moral judgement in making new rules, they systematically act politically, with the same power and freedom (on a smaller scale) as a legislature. It is sometimes said that, with its openness to theoretical ascent, the holistic approach makes the common law vulnerable to excessive "judicial activism", ${ }^{64}$ where the judges act politically in the development of the law. In fact, under the holistic approach the standpoint constraint provides a "middle way" between formalism and politicisation. ${ }^{65}$ If judges could lay down new rules free of the standpoint constraint, they could in theory draw on the broadest range of views about how society should be organised for the benefit of individuals and in the public interest, and this would certainly amount to the exercise of political judgement. However, if judges develop the law subject to the standpoint constraint, they exercise moral judgement only insofar as it is an unavoidable part of adjudication in the common law, and in a very constrained way that can reasonably be said to be non-political. The problem arises instead under the individual rule approach. Under the individual rule approach, the courts might be confined to narrow interstitial development of the law, but insofar as they are free to develop the law more widely, in the absence of rules previously laid down, or by virtue of a power to overrule previous decisions, the risk of excessive judicial activism is far greater because of the openness of the law to the full range of possible arguments, free of the standpoint constraint.

One might think that, having arrived at a just resolution of a dispute from the parties' standpoint, a court should be able to go on and lay down new rules under the individual rule approach, free of the standpoint constraint, with prospective effect, as a legislature would. This would not be unjust to the parties to the litigation, or to others with respect to past events. It would, however, require significant procedural changes, because the parties to the dispute would have no direct interest in what rule is laid down prospectively, and the court would presumably have to allow

\footnotetext{
${ }^{64}$ See e.g. Sunstein, above n31, at 38-9 and 44-6; Shapiro, above n37, 33. One might equate this with the objection to "judicial activism, taken to extremes" and to "excessive innovation and adventurism" by judges: Tom Bingham, The Rule of Law (Penguin Books, 2010) at 45-46.

${ }^{65} \mathrm{Cf}$ Duncan Kennedy, "The Distinction between Adjudication and Legislation", in A Critique of Adjudication (fin de siècle) (Harvard University Press, 1997).
} 
Author: Peter Jaffey, University of Leicester

representation for other interested parties, and evidence relating to matters that would not normally be relevant to adjudication. ${ }^{66}$ More importantly, the problem of political legitimacy would reappear. Because the standpoint constraint would not apply, in order to safeguard their political legitimacy judges should in general be precluded from making rules with prospective effect separately from rules laid down in adjudication.

\section{CONCLUSION}

I have distinguished two approaches to precedent, the individual rule approach and the holistic approach. Under the individual rule approach, a precedent created by the decision of a court is a binding rule and the law consists of the aggregation of these distinct rules. On the holistic approach, the rules devised and applied in previous decisions do not constitute the law - they are in effect provisional rules - and instead to find the law judges construct rules to be consistent with the outcomes of previous cases on their facts. The law amounts to an account of justice that is consistent with the previous decisions, and precedents are not binding rules but decisions that contribute to the determination of the law.

Textbooks and practitioner books often assume the individual rule approach, setting out the rules as definitive and not as merely approximate or provisional, though they may be presented as an incomplete statement of the law. Learning the law is about accumulating knowledge of all the rules of the relevant area, and anything beyond this is a matter of making new law, and is not itself a matter of law. ${ }^{67}$ The individual rule approach has some support in the common law, but the holistic approach is closer to capturing the basic features of common law reasoning. It explains the usual understanding of the ratio of a decision, and other features of the traditional understanding of the common law, such as the practice of distinguishing, the declaratory theory of law and the gapless or continuous character of the common law, analogical and coherence reasoning, the importance of

\footnotetext{
${ }^{66}$ See Hugh Collins, Regulating Contracts (OUP, 1999), 86-7; Tsachi Keren-Paz, Torts, Egalitarianism and Distributive Justice (Ashgate, 2007).

${ }^{67} \mathrm{Cf}$ Beever, above n19, 443.
} 
Author: Peter Jaffey, University of Leicester

legal principles as a distinct element in the law, to be distinguished from moral principles and legal rules, and the heavily fact-focussed and narrative common law style of judgement. These basic features of the common law seem quite incompatible with the individual rule approach.

If the two approaches are compared as methods of determining a just outcome in the absence of a binding rule, the holistic approach appears superior, because, in the absence of a binding rule, the holistic approach draws on judges' decisions collectively and allows for analogical and coherence reasoning, legal principles and theoretical ascent, whereas the individual rule approach simply aggregates rules made separately and independently by courts in different cases.

The attraction of the individual rule approach for its proponents may be that it is thought to come closer to satisfying the standard requirement of the rule of law that people are judged according to binding rules previously announced. However, the requirement cannot be fully met under the individual rule approach, and there is no reason to think it cannot largely be met under the holistic approach. The holistic approach can give rise to settled law, where it would ordinarily operate indistinguishably from the individual rule approach. Furthermore, the value of guidance provided by the law is enhanced under the holistic approach by the fact that it is likely to produce a more just and a more transparent body of rules.

Furthermore, with respect to new rules that are laid down in adjudication and applied to events that have already occurred, the rule of law requires that the rule must be devised from the parties' standpoint, that is to say on the basis of facts known or accessible to ordinary subjects of the law, and excluding other considerations, which a legislature would be able to take account of if it were devising rules for legislation to take effect prospectively. This standpoint constraint is necessary to avoid unfairly retrospective rules, and it also has the effect of limiting the scope for political judgement in the decision-making of the courts. A further advantage of the holistic approach is that, because analogical and coherence reasoning necessarily adopt the parties' standpoint, the holistic approach naturally subjects the courts to the standpoint constraint in developing the law. 
Author: Peter Jaffey, University of Leicester 